\title{
Desempenho de novilhas leiteiras alimentadas com silagem de capim-elefante com adição de diferentes níveis de bagaço de mandioca
}

\author{
[Performance of dairy heifers fed on elephantgrass silage added with different levels of cassava bagasse]

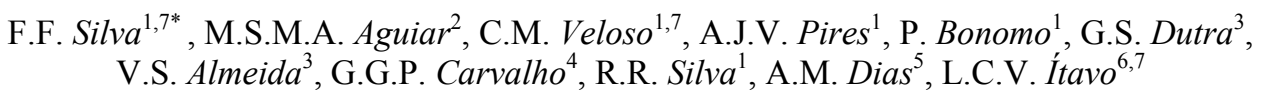 \\ ${ }^{1}$ Universidade Estadual do Sudoeste da Bahia \\ Praça Primavera, 40 \\ 45700-000 - Itapetinga, BA \\ ${ }^{2}$ Escola Agrotécnica Federal - Guanambi, BA \\ ${ }^{3}$ Aluno de graduação - UESB - Bolsista da FAPESB \\ ${ }^{4}$ Aluno de pós-graduação - UFV-Viçosa, $M G$ \\ ${ }^{5}$ Aluno de pós-graduação - UESB-Itapetinga, BA \\ ${ }^{6}$ Universidade Católica Dom Bosco - Campo Grande, MS \\ ${ }^{7}$ Bolsista do $\mathrm{CNPq}$
}

\begin{abstract}
RESUMO
Avaliou-se o efeito da adição de diferentes níveis (5; 10; 15 e 20\%) de bagaço de mandioca na ensilagem do capim-elefante (Pennisetum purpureum, Schum) sobre o desempenho de novilhas leiteiras. Utilizaramse 16 novilhas $3 / 4$ Holandês $\times$ Zebu, com idade média de 15 meses e peso vivo inicial de $144 \mathrm{~kg}$, com quatro repetições por tratamento. $\mathrm{O}$ experimento constou de 14 dias de adaptação, quando as novilhas receberam apenas silagem, e 56 dias de período experimental. Realizaram-se pesagens e tomadas as medidas da altura de cernelha e da circunferência torácica, após jejum de 16 horas, no início do experimento e no $28^{\circ}$ e $56^{\circ}$ dias. Os consumos médios diários de matéria seca (MS) e proteína bruta não diferiram entre tratamentos $(\mathrm{P}>0,05)$. Os consumos médios de fibra em detergente neutro e fibra em detergente ácido apresentaram comportamento linear decrescente $(\mathrm{P}<0,05)$. O desempenho foi verificado por meio das médias do peso vivo inicial, do peso vivo final, do ganho de peso médio diário, do aumento de perímetro torácico, do aumento de altura de cernelha e da conversão alimentar da MS. Não se observou influência dos tratamentos $(\mathrm{P}>0,05)$ sobre as características estudadas.
\end{abstract}

Palavras-chave: bovino leiteiro, consumo, ganho de peso, resíduo, subproduto

\begin{abstract}
The effect of cassava bagasse addition levels (5, 10, 15 and 20\%) to elephantgrass silage on dairy heifers performance was evaluated. Sixteen $3 / 4$ Holstein $x$ Zebu heifers with 15 months of age and $144 \mathrm{~kg}$ of initial body weight were used in a completely randomized block design with four replicates and four treatments. The experiment was carried out for 56 days after and adaptation period of 14 days in which the heifers were fed the respective treatment diets. Weight, withers height and thoracic circumference were recorded often 16 hours fasting at the beginning of the experiment and at days 28 and 56. No differences between treatments were observed for day mother (DM) and crude protein daily intake. The neutral detergent fiber and acid detergent fiber showed a linear reduction behavior. No treatment effects were observed for final body weight, daily weight gain, thoracic perimeter, withers height and DM feed efficiency
\end{abstract}

Keywords: dairy heifer, intake, weight gain, residue, by product

Recebido em 15 de abril de 2004

Aceito em 17 de novembro de 2005

*Autor para correspondência (corresponding author)

E-mail: ffsilva@uesb.br 


\section{INTRODUÇÃO}

O capim-elefante (Pennisetum purpureum, Schum) é uma das plantas forrageiras mais difundidas no país. Por ser perene, de alto potencial de produção e pela sua qualidade, apresenta-se como alternativa economicamente mais atrativa do que o uso de uma cultura anual para produção de silagem (Corral et al., 1981).

Lavezzo (1985) sugere que, para a produção de silagem, o capim-elefante deve ser cortado com 50 a 60 dias de desenvolvimento, após a uniformização, quando a planta apresenta melhor valor nutritivo. Contudo, verifica-se que o teor de matéria seca (MS) da planta, nessa idade, é muito baixo (15 a 20\%), o que não é recomendado para o processo de ensilagem. Para obter uma silagem de bom valor nutritivo, Faria (1986) observou que o teor de MS para a fermentação adequada está entre 30 e 35\%, dependendo da espécie a ser utilizada.

O problema do excesso de umidade da forragem na ensilagem, quando a planta tem alto valor nutritivo, tem merecido a atenção de muitos autores (Van Soest, 1982; Vilela, 1998). Para a redução do excesso de umidade da forragem na ensilagem, uma das alternativas seria a adição de produtos ricos em matéria seca ou de tratamentos que eliminem o excesso de umidade pelo processo de emurchecimento da forragem.

$\mathrm{O}$ aditivo mais utilizado na ensilagem do capimelefante é o material seco, usado para elevar o teor de MS da silagem, aumentando as chances de boa preservação. O material mais tradicional utilizado é a fonte de carboidratos, como o fubá de milho, o farelo de trigo, a polpa cítrica e os resíduos regionais da agroindústria. Dentre os resíduos do processamento industrial da mandioca, além da raiz, podem ser utilizados outros subprodutos. $\mathrm{Na}$ região de Vitória da Conquista, BA, existem muitas microagroindústrias de farinha e polvilho, e nelas encontra-se um subproduto com preço acessível, resultante da produção do polvilho, que é o bagaço de mandioca, o qual tem sido fornecido, com resultados satisfatórios, para bovinos em engorda (Silveira, 1995).

De acordo com Ramos et al. (2000), o bagaço de mandioca é um subproduto da industrialização da mandioca para a fabricação de polvilho, obtido após lavagens consecutivas da massa de mandioca. Segundo Butriago (1990), pode conter até $60 \%$ de amido, e constitui uma fonte de carboidrato rapidamente fermentável. Contudo, não há muitas informações científicas sobre sua utilização para ruminantes.

Campos Neto (1996), citado por Abrahão (2000), constatou que os resíduos da industrialização da mandioca assemelham-se às raízes em termos de composição química, por apresentarem elevado teor de carboidratos não estruturais. Portanto, dados relativos à composição das raízes e seus produtos diretos relacionam-se aos obtidos com resíduos. Enquanto a raiz integral apresenta cerca de $94 \%$ de carboidratos, os resíduos oriundos da extração de fécula têm até $75 \%$ de amido (Cereda, 1994), mas devem se comportar de maneira semelhante quando utilizados na formulação de rações para bovinos.

Abrahão et al. (1997), ao pesquisarem a inclusão do resíduo de fecularia ensilado em dietas com silagem de sorgo, cana-de-açúcar ou ambos, obtiveram ganho de peso superior a $1 \mathrm{~kg} /$ animal/dia, com novilhas cruzadas que consumiam elevada proporção de resíduo ensilado $(45 \%$ da dieta entre resíduos + suplemento protéico).

Novilhos em sistema de pastejo com capimelefante alcançaram ganho médio diário de 1,06 $\mathrm{kg} /$ dia e $963 \mathrm{~kg}$ de ganho de peso vivo/ha, segundo Almeida et al. (2000). Assim, o objetivo deste trabalho foi avaliar o desempenho de novilhas mestiças que receberam dietas com silagem de capim-elefante aditivada com diferentes níveis de bagaço de mandioca.

\section{MATERIAL E MÉTODOS}

O capim-elefante utilizado foi da variedade Napier, cortado manualmente, rente ao solo, com 80 dias de idade, picado em picadeira estacionária, homogeneizado e imediatamente ensilado. Os tratamentos foram constituídos de quatro níveis de inclusão de bagaço de mandioca às silagens de capim-elefante, na base da matéria natural, quais sejam: 5, 10, 15 e 20\%. A forragem foi ensilada em silos do tipo superfície, com dimensões que permitiram a retirada das fatias de corte superiores a $20 \mathrm{~cm}$ por dia. O bagaço de mandioca devidamente pesado, de 
acordo com a proporção de cada tratamento, foi adicionado à forragem na medida em que o material picado era colocado no silo, e de maneira a manter distribuição homogênea do material no processo de enchimento.

Utilizaram-se 16 novilhas $3 / 4$ Holandês-Zebu, com peso vivo médio de $144 \pm 18 \mathrm{~kg}$ e idade média de 15 meses, identificadas com brincos numerados. Os animais foram alojados em baias individuais cobertas, com piso de concreto, providas de cocho individual de concreto para alimentação e bebedouro automático, comum a duas baias. No início do experimento, as novilhas foram pesadas e distribuídas em quatro tratamentos, com delineamento inteiramente ao acaso, com quatro tratamentos e quatro repetições.

Os animais passaram por um período de adaptação de 14 dias, durante os quais foram alimentados somente com as silagens aditivadas dos tratamentos. Após o período de adaptação, foram submetidos aos respectivos tratamentos, sendo alimentados com o concentrado e a silagem. As dietas contendo a silagem de capim-elefante com bagaço de mandioca foram calculadas para conterem nutrientes suficientes para ganho de peso vivo (PV) de $0,70 \mathrm{~kg} / \mathrm{dia}$, de acordo com o NRC (Nutrient..., 2001), com base nos dados da análise bromatológica das silagens, previamente feita no início do período de adaptação. O teor de nutrientes digestíveis totais (NDT) foi estimado a partir da equação de regressão $\mathrm{NDT}=74,49$ $-0,5635^{*}$ FDA $\left(r^{2}=0,84\right)$, descrita por Capelle et al. (2001), para volumosos. A relação volumoso:concentrado encontrada na dieta do tratamento com $5 \%$ foi a mesma utilizada em todas as outras dietas dos demais tratamentos. Todas foram calculadas para serem isoprotéicas.

As proporções dos ingredientes nos concentrados são apresentadas na Tab. 1, na base da matéria natural, de acordo com o nível de bagaço de mandioca. Para esses cálculos estimativos, foram compiladas da literatura as composições químicas da silagem de capim-elefante e dos ingredientes do concentrado, de acordo com Capelle (2000), encontrando-se uma relação volumoso:concentrado de 60:40, na base da MS.

Tabela 1. Proporção dos ingredientes nos concentrados (\%), na base da matéria natural, utilizados nas dietas de novilhas leiteiras, contendo silagem de capim-elefante aditivada com diferentes níveis de bagaço de mandioca

\begin{tabular}{|c|c|c|c|c|}
\hline \multirow{2}{*}{ Ingrediente } & \multicolumn{4}{|c|}{ Nível de bagaço de mandioca na silagem (\%) } \\
\hline & 5 & 10 & 15 & 20 \\
\hline Fubá de milho & 57,00 & 56,20 & 55,50 & 54,70 \\
\hline Farelo de soja & 36,90 & 37,70 & 38,40 & 39,20 \\
\hline Uréia & 2,00 & 2,00 & 2,00 & 2,00 \\
\hline Sulfato de amônia & 0,30 & 0,30 & 0,30 & 0,30 \\
\hline Calcário calcítico & 1,70 & 1,70 & 1,70 & 1,70 \\
\hline Fosfato bicálcico & 1,20 & 1,20 & 1,10 & 1,10 \\
\hline Sal mineral $^{1}$ & 1,00 & 1,00 & 1,00 & 1,00 \\
\hline
\end{tabular}

A ração foi fornecida duas vezes ao dia (às $7 \mathrm{e}$ 17 horas), sendo a quantidade calculada de modo a permitir sobras entre 5 e 10\% Para as análises dos alimentos oferecidos (silagem e concentrado) e das sobras adotou-se a rotina recomendada para experimentos dessa natureza. Foram calculados os consumos diários de MS e dos nutrientes: proteína bruta $(\mathrm{PB})$, fibra em detergente neutro (FDN), fibra em detergente ácido (FDA) e NDT, expressos em quilogramas por dia ( $\mathrm{kg} / \mathrm{dia})$ em \% do PV e em relação ao tamanho metabólico $\left(\mathrm{g} / \mathrm{kg}^{0,75}\right)$.
As determinações de MS, nitrogênio total, extrato etéreo (EE), matéria mineral $(\mathrm{MM})$, cálcio $(\mathrm{Ca})$ e fósforo $(\mathrm{P})$ foram realizadas conforme técnicas descritas por Cunniff (1995). A solução mineral para determinação dos macroelementos foi preparada por via seca. Após as devidas diluições, o teor de Ca foi determinado por titulação com EDTA 0,025 N (quelato métrico) e o de P por colorimetria. A FDN e a FDA foram determinadas pelo método seqüencial de Robertson e Van Soest (1981). Nas análises de FDN e FDA dos 
concentrados, silagens e sobras foi adicionada amilase termo-estável para minimizar a interferência do amido. Os carboidratos nãofibrosos foram obtidos pela relação $\mathrm{CNF}=[100-$ $(\% \mathrm{~PB}+\% \mathrm{EE}+\% \mathrm{MM}+\% \mathrm{FDN})]$.

A composição química das dietas encontra-se na Tab. 2
O período experimental teve duração de 56 dias, sendo realizadas pesagens e tomadas as medidas de altura de cernelha e circunferência torácica dos animais, após jejum de 16 horas, no início do experimento, no $28^{\circ}$ e $56^{\circ}$ dias, para determinação do ganho de PV, altura de cernelha e circunferência torácica.

Tabela 2. Teores médios de matéria seca (MS), matéria orgânica (MO), proteína bruta (PB), extrato etéreo (EE), fibra em detergente neutro (FDN), fibra em detergente ácido (FDA), carboidratos não fibrosos $(\mathrm{CNF})$, cálcio $(\mathrm{Ca})$ e fósforo $(\mathrm{P})$, obtidos para as quatro rações experimentais

\begin{tabular}{lcccc}
\hline \multirow{2}{*}{ Item } & \multicolumn{4}{c}{ Nível de bagaço de mandioca na silagem $(\%)$} \\
\cline { 2 - 5 } & 5 & 10 & 15 & 20 \\
\hline MS (\%) & 34,92 & 38,55 & 41,82 & 43,36 \\
MO $^{1}$ & 92,33 & 92,96 & 93,82 & 93,67 \\
PB $^{1}$ & 13,55 & 13,88 & 13,61 & 14,07 \\
EE $^{1}$ & 3,33 & 3,09 & 3,08 & 2,85 \\
FDN $^{1}$ & 48,97 & 42,94 & 38,70 & 36,79 \\
FDA $^{1}$ & 27,49 & 23,59 & 20,86 & 19,91 \\
CNF $^{1}$ & 26,49 & 33,05 & 38,42 & 39,95 \\
Ca $^{1}$ & 0,694 & 0,738 & 0,689 & 0,678 \\
P $^{1}$ & 0,298 & 0,343 & 0,273 & 0,334 \\
\hline
\end{tabular}

${ }^{1}$ Porcentagem na MS.

Para as análises de variância e de regressão utilizou-se o sistema de análises estatísticas e genéticas (Sistema... 2001). O critério usado para a escolha do modelo de regressão foi 0 coeficiente de determinação ajustado, em porcentagem. Os coeficientes de regressão individuais foram testados pelo teste t a $5 \%$ de probabilidade.

\section{RESULTADOS E DISCUSSÃO}

Na Tab. 3 são apresentados os consumos médios diários de MS, PB, FDN e FDA, com as respectivas equações de regressão e coeficientes de variação de determinação.

O consumo de MS foi semelhante entre os tratamentos $(\mathrm{P}>0,05)$. Os valores médios de consumo de MS, expressos em $\mathrm{kg} / \mathrm{dia}$, \% PV e $\mathrm{g} / \mathrm{kg}^{0,75}$, foram 5,56; 3,2 e 115,42, respectivamente. Não ocorreu aumento no consumo de MS com o aumento da inclusão do bagaço na silagem, talvez pelo fato de o valor energético do bagaço ser semelhante ao da silagem de capim-elefante. Ramos et al. (2000), ao trabalharem com o bagaço de mandioca em substituição ao milho no concentrado de novilhos, verificaram que em níveis acima de $48,74 \%$ o consumo de MS foi reduzido. O valor máximo encontrado foi $88,53 \mathrm{~g} / \mathrm{kg}^{0,75}$.

Jorge et al. (2002), ao alimentarem novilhos da raça Holandesa com diferentes níveis de substituição do milho pela farinha de varredura de mandioca $(0,25,50,75$ e $100 \%)$, verificaram que o consumo de MS em relação ao PV dos animais foi linear decrescente segundo $\mathrm{O}$ aumento do nível de substituição $(2,4$ a $2,2 \%$ do $\mathrm{PV}$ ), valores abaixo do encontrado no presente experimento, $3,2 \%$.

Os valores médios de consumo de $\mathrm{PB}$, expressos em $\mathrm{kg} / \mathrm{dia}, \% \mathrm{PV}$ e $\mathrm{g} / \mathrm{kg}^{0,75}$, foram 0,$70 ; 0,40$ e 14,46, respectivamente. $\mathrm{O}$ consumo de $\mathrm{PB}$ não diferiu entre os tratamentos, pois as dietas foram padronizadas para conter valores protéicos próximos (Tab. 2). Caldas Neto et al. (2000), ao estudarem o consumo de PB por novilhos alimentados com dietas à base de silagem de milho com casca e com raspa de mandioca desidratada, com aproximadamente $14 \%$ de PB, verificaram valores de $0,20 \% \mathrm{PV}$, inferior ao $0,40 \%$ PV observado neste experimento. Ramos et al. (2000), ao testarem o bagaço de mandioca em substituição ao milho no concentrado $(0,33$, 66 e 99\%) para novilhos, observaram que o consumo máximo de $\mathrm{PB}$ foi $10,61 \mathrm{~g} / \mathrm{kg}^{0,75}$ para o nível de $43,8 \%$ de substituição do bagaço,valor mais baixo que o desta pesquisa $\left(14,46 \mathrm{~g} / \mathrm{kg}^{0,75}\right)$. 
Tabela 3. Médias, coeficientes de variação (CV, \%) e equações de regressão ajustadas dos consumos diários de matéria seca (MS), proteína bruta (PB), fibra em detergente neutro (FDN) e fibra em detergente ácido (FDA) e respectivos coeficientes de determinação

\begin{tabular}{|c|c|c|c|c|c|c|c|}
\hline & \multicolumn{4}{|c|}{ Nível de bagaço de mandioca na silagem (\%) } & \multirow{2}{*}{ Regressão } & \multirow{2}{*}{$\mathrm{R}^{2}$} & \multirow{2}{*}{$\mathrm{CV}$} \\
\hline & 5 & 10 & 15 & 20 & & & \\
\hline \multicolumn{8}{|c|}{ Consumo de MS } \\
\hline $\mathrm{kg} / \mathrm{dia}$ & 5,52 & 5,21 & 6,38 & 5,10 & $Y=5,56$ & - & 13,95 \\
\hline$\%$ peso vivo & 3,27 & 3,00 & 3,45 & 3,00 & $\mathrm{Y}=3,18$ & - & 6,62 \\
\hline $\mathrm{g} / \mathrm{kg}^{0,75}$ & 118,00 & 108,89 & 127,15 & 107,89 & $Y=115,42$ & - & 7,37 \\
\hline \multicolumn{8}{|c|}{ Consumo de PB } \\
\hline kg/dia & 0,670 & 0,652 & 0,808 & 0,660 & $\mathrm{Y}=0,700$ & - & 14,36 \\
\hline$\%$ peso vivo & 0,395 & 0,373 & 0,440 & 0,385 & $\mathrm{Y}=0,400$ & - & 8,02 \\
\hline $\mathrm{g} / \mathrm{kg}^{0,75}$ & 14,212 & 13,544 & 16,175 & 13,923 & $Y=14,464$ & - & 7,77 \\
\hline \multicolumn{8}{|c|}{ Consumo de FDN } \\
\hline $\mathrm{kg} / \mathrm{dia}$ & 2,60 & 2,14 & 2,37 & 1,79 & $Y=2,77143-0,0438 X$ & 0,67 & 14,72 \\
\hline$\%$ peso vivo & 1,54 & 1,23 & 1,28 & 1,05 & $\mathrm{Y}=1,63488-0,0288 \mathrm{X}$ & 0,82 & 7,04 \\
\hline \multicolumn{8}{|c|}{ Consumo de FDA } \\
\hline $\mathrm{kg} / \mathrm{dia}$ & 1,46 & 1,17 & 1,26 & 0,970 & $Y=1,56727-0,0436 X$ & 0,77 & 15,08 \\
\hline$\%$ peso vivo & 0,867 & 0,674 & 0,680 & 0,558 & $\mathrm{Y}=0,92480-0,0184 \mathrm{X}$ & 0,86 & 7,40 \\
\hline
\end{tabular}

O consumo de FDN, expresso em $\mathrm{kg} / \mathrm{dia}$ e \% PV, apresentou comportamento linear decrescente com o aumento do nível de bagaço (Tab. 3), devido à redução de FDN na dieta. Os valores médios foram 49,$0 ; 42,9 ; 38,7$ e $36,8 \%$ para os tratamentos com 5, 10, 15 e $20 \%$ de substituição. Conforme discutido, os teores de FDN não influenciaram o consumo de MS.

Os resultados da ingestão de FDN para as dietas mostraram que os animais ingeriram acima da capacidade considerada ótima para o consumo de FDN, que, segundo Mertens (1985), é de 1\%PV para animais em crescimento. Mertens (1987) relatou ser importante que o teor de FDN não limite a ingestão para que os animais sejam capazes de consumir quantidade suficiente de MS que atenda às suas necessidades energéticas, e não influencie a produção.

O consumo de FDN variou de 1,5 a 1,0\% PV e não limitou o consumo. Martins (1999) verificou valores de 0,85 e $1,2 \%$ PV para dietas contendo silagem de milho associada com casca de mandioca em razão da fonte protéica, levedura ou farelo de algodão, respectivamente, em novilhas confinadas. Marques (1999) verificou valores de 0,$85 ; 0,98$ e $0,75 \%$ PV para silagem de milho, casca e raspa de mandioca, respectivamente.

O consumo de FDA, expresso em $\mathrm{kg} / \mathrm{dia}$ e \% PV, apresentou comportamento linear decrescente com o aumento do nível de bagaço (Tab. 3), devido à redução da FDA na dieta. Os valores médios foram de 27,$5 ; 23,6 ; 20,9$ e $19,9 \%$, para os tratamentos com 5, 10, 15 e 20\% de bagaço de mandioca,. Neste trabalho, os teores de FDA na dieta não restringiram o consumo de MS, e a equação de regressão foi: consumo de FDA = $0,92480-0,0184066 X\left(\mathrm{P}<0,05 ; \mathrm{R}^{2}=0,86\right)$. O consumo de FDA variou de 0,88 a $0,57 \%$ PV. Ramos et al. (2000) observaram que o consumo de FDA digestível elevou-se linearmente com o aumento da substituição do milho por bagaço de mandioca, o que é esperado, pois o conteúdo de FDA do bagaço de mandioca é bem maior que o do milho (29,4 vs 3\%).

O consumo de FDA foi decrescente, de 1,46 a $0,97 \mathrm{~kg} /$ dia. Marques et al. (2000), ao trabalharem com novilhas, verificaram consumo de 2,20 a $1,50 \mathrm{~kg} / \mathrm{dia}$, ao substituírem milho pela casca, farinha de varredura e raspa de mandioca.

$\mathrm{Na}$ Tab. 4 são apresentados os resultados de desempenho de acordo com os tratamentos.

Não houve diferença para PV inicial e PV final $(\mathrm{P}>0,05)$ entre os tratamentos. Em 56 dias, os ganhos de peso total foram, em média, 54,50; 59,$25 ; 71,75$ e $54,00 \mathrm{~kg}$, respectivamente, para os tratamentos 5, 10, 15 e $20 \%$. A média de ganho foi $59,88 \mathrm{~kg}$.

O ganho médio diário de peso não diferiu $(\mathrm{P}>0,05)$ entre os tratamentos, sendo a média de ganho igual a $1,07 \mathrm{~kg}$. Esse resultado pode ser 
atribuído, parcialmente à baixa condição corporal dos animais antes do experimento e ao elevado consumo de MS. No início do experimento, os animais apresentaram maior velocidade de ganho de peso. Como as dietas foram balanceadas para os animais adquirirem em torno de $0,7 \mathrm{~kg} / \mathrm{dia}$, o consumo de MS foi alto, com reflexo no ganho de peso diário.

Tabela 4. Médias e coeficientes de variação ( $\mathrm{CV}, \%)$ para o peso vivo inicial, peso vivo final, ganho de peso médio diário, aumento de perímetro torácico, aumento de altura de cernelha e conversão alimentar da matéria seca, em função dos níveis de bagaço de mandioca na silagem

\begin{tabular}{lcccccc}
\hline \multirow{2}{*}{ Item } & \multicolumn{3}{c}{ Nível de bagaço de mandioca na silagem (\%) } & \multirow{2}{*}{ Regressão } & CV \\
\cline { 2 - 5 } & 5 & 10 & 15 & 20 & & \\
\hline Peso vivo inicial $(\mathrm{kg})$ & 142,00 & 143,50 & 148,75 & 144,50 & $\mathrm{Y}=144,68$ & 12,37 \\
Peso vivo final $(\mathrm{kg})$ & 196,50 & 202,75 & 220,50 & 198,50 & $\mathrm{Y}=204,56$ & 12,53 \\
Ganho médio diário (kg/dia) & 0,975 & 1,057 & 1,282 & 0,965 & $\mathrm{Y}=1,07$ & 22,96 \\
Aumento do perímetro torácico (cm/dia) & 0,223 & 0,245 & 0,285 & 0,236 & $\mathrm{Y}=0,248$ & 20,06 \\
Aumento da altura da cernelha (cm/dia) & 0,098 & 0,111 & 0,116 & 0,102 & $\mathrm{Y}=0,107$ & 16,46 \\
Conversão alimentar & 5,76 & 4,95 & 5,09 & 5,53 & $\mathrm{Y}=5,33$ & 16,77 \\
\hline
\end{tabular}

Ferreira et al. (1989) não encontraram diferenças significativas no ganho de peso médio diário de novilhos que consumiam milho em grão $(100 \%)$ ou milho e raspa de mandioca (50:50) como fonte energética no concentrado. Segundo os autores, o consumo de MS também não diferiu entre os tratamentos.

A altura de cernelha e o perímetro torácico (Tab. 4) não diferiram entre os tratamentos $(\mathrm{P}>0,05)$. Miranda et al. (1999), ao pesquisarem o desempenho e o desenvolvimento ponderal de novilhas leiteiras alimentadas com dietas à base de cana-de-açúcar, não observaram diferença significativa em relação ao aumento na altura de cernelha $(0,05 \mathrm{~cm} / \mathrm{dia})$ e no perímetro torácico $(0,08 \mathrm{~cm} / \mathrm{dia})$.

A conversão alimentar (CA) da MS não diferiu entre os tratamentos $(\mathrm{P}>0,05)$, pois o consumo de MS não diferiu entre os tratamentos e o consumo de FDN não limitou o consumo de MS. Observou-se, então, que nenhuma dieta limitou fisicamente o consumo a ponto de limitar o desempenho dos animais. Os resultados positivos de CA estão de acordo com o bom desempenho dos animais, independente do nível de bagaço de mandioca na silagem. Marques et al. (2000) também não observaram diferença de $\mathrm{CA}$, ao testarem a substituição do milho pela casca, farinha de varredura e raspa de mandioca em novilhas confinadas, obtendo média de 6,6.

\section{CONCLUSÕES}

O nível de adição de 5\% de bagaço de mandioca à silagem de capim-elefante é satisfatório, propiciando bom consumo e bom desempenho animal, não sendo necessária a adição de bagaço de mandioca em níveis mais elevados.

\section{REFERÊNCIAS BIBLIOGRÁFICAS}

ABRAHÃO, J.J.S. Diferentes subprodutos da mandioca na alimentação de bovinos visando a produção de carne e leite. 2000. 82f. Dissertação (Mestrado em Zootecnia) - Universidade Estadual de Maringá, Maringá, PR.

ABRAHÃO, J.J.S.; PEROTTO, D.; MOLETTA, J.L. Avaliação da substituição da silagem de sorgo por cana-de-açúcar em dietas com resíduos de fecularia no desempenho de novilhas. In: REUNIÃO ANUAL DA SOCIEDADE BRASILEIRA DE ZOOTECNIA, 34., Juiz de Fora. Anais... Juiz de Fora: SBZ, 1997.

ALMEIDA, E.X.; MARASCHIN, G.E.; HARTHMANN, O.E.L. et al. Oferta de forragem de capim-elefante anão "mott" e o rendimento animal. Rev. Bras. Zootec., v.29, p.1288-1295, 2000 .

BUTRIAGO, J.A.A. Layuca en la alimentation animal. Cali, 1990. 446 p.

CALDAS NETO, S.F.; ZEOULA, L.M.; BRANCO A.F. Mandioca e resíduos das farinheiras na alimentação de ruminantes: digestibilidade total e parcial. Rev. Bras. Zootec., v.29, p.2099-2108, 2000. 
CAPELLE, E.R. Tabelas de composição dos alimentos, estimativa do valor energético $e$ predição do consumo e do ganho de peso de bovinos. 2000. 369f. Tese (Doutorado em Zootecnia) - Universidade Federal de Viçosa, Viçosa, MG.

CAPELLE, E.R.; VALADARES FILHO, S.C.; SILVA, J.F.C. et al. Estimativas do valor energético a partir de características químicas e bromatológicas dos alimentos. Rev. Bras. Zootec., v.30, p.1837-1856, 2001.

CEREDA, M.P. Caracterização dos resíduos da industrialização da mandioca. In:__. (Ed.). Resíduos da industrialização da mandioca. Botucatu, 1994. p. 11-50.

CORRAL, A.J.; NEAL, H.D.; WILKINSON, J.M. The influence of forage management and conservation strategies on economic margin in a dairy enterprise. Technol. Rep. Grassil Res. Inst., n.29, p.1-48, 1981.

CUNNIFF, P. (Ed.). Official methods of analysis of AOAC International. 16.ed. Arlington: AOAC International, 1995. v.1.

FARIA, V.P. Técnicas de produção de silagens. In: CONGRESSO BRASILEIRO DE PASTAGENS, 1., 1986, Piracicaba. Anais... Piracicaba: FEALQ, 1986. p.119-144.

FERREIRA, J.J.; NETO, J.M.; MIRANDA, E.S. Efeito do milho, sorgo e raspa de mandioca na ração sobre o desempenho de novilhas confinadas. Rev. Bras. Zootec., v.18, p.306-313, 1989.

JORGE, J.R.V.; ZEOULA, L.M.; PRADO, I.N. et al. Substituição do milho pela farinha de varredura (Manihot esculenta, Crantz) na ração de bezerros holandeses. 1. Desempenho e parâmetros sangüíneos. Rev. Bras. Zootec., v.31, p.192-204, 2002.

LAVEZZO, W. Silagem de capim-elefante. Inf. Agrop., v.11, p.50-57,1985.

MARQUES, J.A Avaliação da mandioca e seus resíduos industriais em substituição do milho na terminação de novilhas: desempenho $e$ digestibilidade aparente in vivo. 1999. 42f. Dissertação (Mestrado em Zootecnia) Universidade Estadual de Maringá, Maringá, PR .

MARQUES, J.A.; PRADO, I.N; ZEOULA, L.M. et al. Avaliação da mandioca e seus resíduos industriais em substituição ao milho no desempenho de novilhas confinadas. Rev. Bras. Zootec., v.29, p.1528-1536, 2000.

MARTINS, A.S. Desempenho de novilhas alimentadas com rações contendo milho ou casca de mandioca e farelo de algodão ou levedura. 1999. 84f. Dissertação (Mestrado em Zootecnia) Universidade Estadual de Maringá, Maringá, PR.

MERTENS, D.R. Factors influencing feed intake in lactating cows: from theory to application using neutral detergent fiber. In: GA NUTRITION CONFERENCE, 46., 1985, Athens. Proceedings... Athens: University of Georgia, 1985. p.1-18.

MERTENS, D.R.. Predicting intake and digestibility using mathematical models of ruminal function. J. Anim. Sci., v.64, p.1548-1558, 1987.

MIRANDA, L.F.; QUEIROZ, A.C.; FILHO VALADARES, S.C. et al. Desempenho e desenvolvimento ponderal de novilhas alimentadas com dietas à base de cana-de-açúcar. Rev. Bras. Zootec., v.28, p.605-613, 1999.

NUTRIENT requirement of dairy cattle. 7.ed. Washington, DC: National Academy, 2001. 381p.

RAMOS, P.R.; PRATES, E.R. FONTANELLI, R.S. et al. Uso do bagaço de mandioca em substituição ao milho em concentrado para bovinos em crescimento: 1.Consumo de matéria seca, matéria orgânica e proteína bruta. Rev. Bras. Zootec., v.29, p.295-299, 2000.

ROBERTSON, J.B.; VAN SOEST, P.J. The detergent system of analysis and its application to human foods. In: JAMES, W.P.T., THEANDERM, O. (Eds.). The analysis of dietary fiber in food. New York: Marcel Dekker, 1981. p.123-158.

SILVEIRA, J.A. Tem resíduos virando carne. Granja, v.51, p.41-42, 1995.

SISTEMA de análises estatísticas e genéticas SAEG. Viçosa: UFV, 2001.

VAN SOEST, P.J. Nutritional ecology of the ruminant. Oregon: O \& B Books, 1982. 373p.

VILELA, D. Aditivos para silagens de plantas de clima tropical. In: Simpósio sobre aditivos na produção de ruminantes e não ruminantes, 1 . REUNIÃO ANUAL DA SOCIEDADE BRASILEIRA DE ZOOTECNIA, 35., 1998, Botucatu. Anais... Botucatu: SBZ, 1998. p.73-108. 